\title{
Production of L-Leucine Nanoparticles under Various Conditions Using an Aerosol Flow Reactor Method
}

\author{
Anna Lähde, ${ }^{1}$ Janne Raula, ${ }^{1}$ and Esko I. Kauppinen ${ }^{1,2}$ \\ ${ }^{1}$ NanoMaterials Group, Laboratory of Physics, Helsinki University of Technology, P.O. Box 5100, 02150 Espoo, Finland \\ ${ }^{2}$ VTT Biotechnology, P.O. Box 1000, 02044 VTT, Finland
}

Correspondence should be addressed to Esko I. Kauppinen, esko.kauppinen@tkk.fi

Received 1 August 2007; Revised 3 April 2008; Accepted 22 May 2008

Recommended by Ali Eftekhari

\begin{abstract}
We have studied the formation of L-leucine nanoparticles under various conditions using an aerosol flow reactor method. Temperatures and L-leucine concentrations for the experiments were selected to vary the saturation conditions for L-leucine in the reactor. In the two extreme cases, L-leucine is either in (i) the condensed phase $\left(110^{\circ} \mathrm{C}\right)$ or completely in (ii) the vapour phase $\left(200^{\circ} \mathrm{C}\right)$ for all concentrations; (iii) at the intermediate temperature $\left(150^{\circ} \mathrm{C}\right)$, the extent of evaporation of L-leucine depends notably on the concentration, and thus partial evaporation and production of residual particles are expected. The size distribution of particles and the particle morphology varied according to formation mechanism with the geometric mean diameter of the particles between $30 \mathrm{~nm}$ and $210 \mathrm{~nm}$. Hollow, spherical particles were obtained with the droplet-to-particle method without vaporisation of L-leucine; whereas leafy-looking particles were produced by homogeneous nucleation of supersaturated L-leucine vapour and subsequent growth by heterogeneous vapour deposition.
\end{abstract}

Copyright (C) 2008 Anna Lähde et al. This is an open access article distributed under the Creative Commons Attribution License, which permits unrestricted use, distribution, and reproduction in any medium, provided the original work is properly cited.

\section{INTRODUCTION}

The ability to design and produce pharmaceutical particles with the desired surface properties by particle engineering or by particle surface modification (e.g., coating) offers a great advantage in today's market. Much study has been devoted to the production of stable and dispersible dry-powder aerosol formulations for efficient pulmonary delivery of pharmaceutical agents [1-3].

Amino acid L-leucine is an effective excipient that improves the properties of powder such as dispersibility, flowability, and stability [2, 4-7]. Surface accumulation of L-leucine on drug particle surfaces has been achieved by powder blending $[1,2,7]$, surface-diffusion in spray-drying $[5,6]$ and physical vapour deposition (PVD) $[4,8]$. Among these techniques, the PVD method enables both efficient tailoring of the characteristics of an L-leucine particles and preparation of the coating layers on the surface of the core particles that affects significantly the properties of coated particles [4]. The interaction between particles can be further reduced with the addition of L-leucine nanoparticles, that is, glidants adsorbed on the surface of the micron-sized particles. The glidants decrease the contact area between particles and increase the separation distance depending on the size and shape of the glidants $[9,10]$.

In the gas-phase methods including spray drying and PVD, the particle size and shape are affected by the formation mechanism, that is, droplet-to-particle and gas-to-particle conversion $[8,11]$. Under suitable conditions these methods enable the production of nanoparticles with well-defined structure and size. The residence times in the heated zone are short preventing the material decomposition [8]. Dry nanoparticles are collected directly from the gas phase and are available for use, for example, as glidants without further purification or processing.

In our previous study of L-leucine particles, the evaporation of L-leucine took place from the aerosol L-leucine particles whose mass median particle size was initially larger than $0.8 \mu \mathrm{m}$ [8]. In work presented in this paper, we have extended the study to the particle sizes smaller than $0.8 \mu \mathrm{m}$. The particle number concentrations in the studies are close with only $13 \%$ difference in maximum. It is known that the thermodynamic phenomena of material such as melting and evaporation may change remarkably as particle size decreases [12]. Accordingly, a rapid solvent evaporation from the nanodroplets as well as the small initial size of the dry 
particles is likely to enhance the vaporisation of L-leucine due to the Kelvin effect [12]. As a consequence, the formation of L-leucine nanoparticles in the later stage changes. We aim to deepen the knowledge of L-leucine evaporation and particle formation in the gas phase when L-leucine is introduced as particles notably smaller than in our previous study.

\section{MATERIALS AND METHODS}

\subsection{Materials}

Pharmacopoeia grade L-leucine (Fluka Chem, grade PhEur, Switzerland) was used as received. Prior to particle preparation, five aqueous L-leucine precursor solutions were prepared by dissolving $1.1,2.2,4.3,8.6$, and $17.2 \mathrm{~g}$ of $\mathrm{L}$ leucine in 1 litre of ion-exchanged water $(\mathrm{pH} 6.5)$ at room temperature.

\subsection{Nanoparticle production}

Figure 1 shows the experimental set-up of the reactor. The precursor solution was atomised with a constant output atomiser in the nonrecirculation mode (model 3076, TSI Inc. Particle Instruments, USA) in the feeding Section 1 producing droplets around $300 \mathrm{~nm}$ estimated by the manufacturer. A flow rate of $3.5 \mathrm{~L} / \mathrm{min}$ of carrier gas (nitrogen, $\mathrm{N}_{2}$ ) was used. The average feed rate of precursor solutions through the atomiser was $0.4 \mathrm{~mL} / \mathrm{min}$ controlled with a needle valve. The actual L-leucine concentration in the reactor $\left(C_{\text {reactor }}\right)$ was $0.012,0.029,0.065,0.143$, and $0.318 \mathrm{~g} / \mathrm{m}^{3}$ depending on the L-leucine precursor solution concentrations $\left(C_{\mathrm{le}}\right) 1.1$, $2.2,4.3,8.6$, and $17.2 \mathrm{~g} / \mathrm{L}$, respectively, since only fraction of the droplets with suitable size is carried to the heated zone (Section 2) while the excess liquid is collected to the waste bottle (Figure 1).

After atomisation, the droplets were carried to the heated zone (Section 2) of the reactor, which consisted of a stainless steel tube (inner diameter of $30 \mathrm{~mm}$ and length of $1200 \mathrm{~mm}$ ) placed inside the furnace. The flow in the heated zone was fully laminar. Experiments were carried out at three temperatures 110,150 , and $200^{\circ} \mathrm{C}\left( \pm^{\circ} \mathrm{C}\right)$; and the average residence times in the heated part were 11.1, 10.1, and $9.0 \mathrm{~s}$, respectively. The average residence time $t$ (second) was calculated using the temperature corrected volume flow rate $Q\left(\mathrm{~m}^{3} / \mathrm{s}\right)$ the cross-sectional area of the tube $A\left(\mathrm{~m}^{2}\right)$ and the length of the heated zone $L(m): t=(Q \times 1) / A$. The centreline gas temperatures of the reactor tube were measured with the gas flow at $5 \mathrm{~cm}$ intervals with a $K$-type thermocouple. These temperatures were used in the calculations described in Section 2.4.1.

The aerosol exiting the heated zone was rapidly cooled with a large volume of $\mathrm{N}_{2}$ at ambient temperature at a flow rate of $30 \mathrm{~L} / \mathrm{min}$ using a porous tube (sintered metal tube with pore size $20 \mu \mathrm{m}$ ). The length of the porous tube was $200 \mathrm{~mm}$ with inner diameter of $12.7 \mathrm{~mm}$. In Section 3, the nucleation and subsequent condensation of L-leucine vapour was initiated. The simultaneous cooling and dilution with a dilution ratio of $9.6: 1$ prevented solvent condensation and decreased the wall deposition losses of dry L-leucine
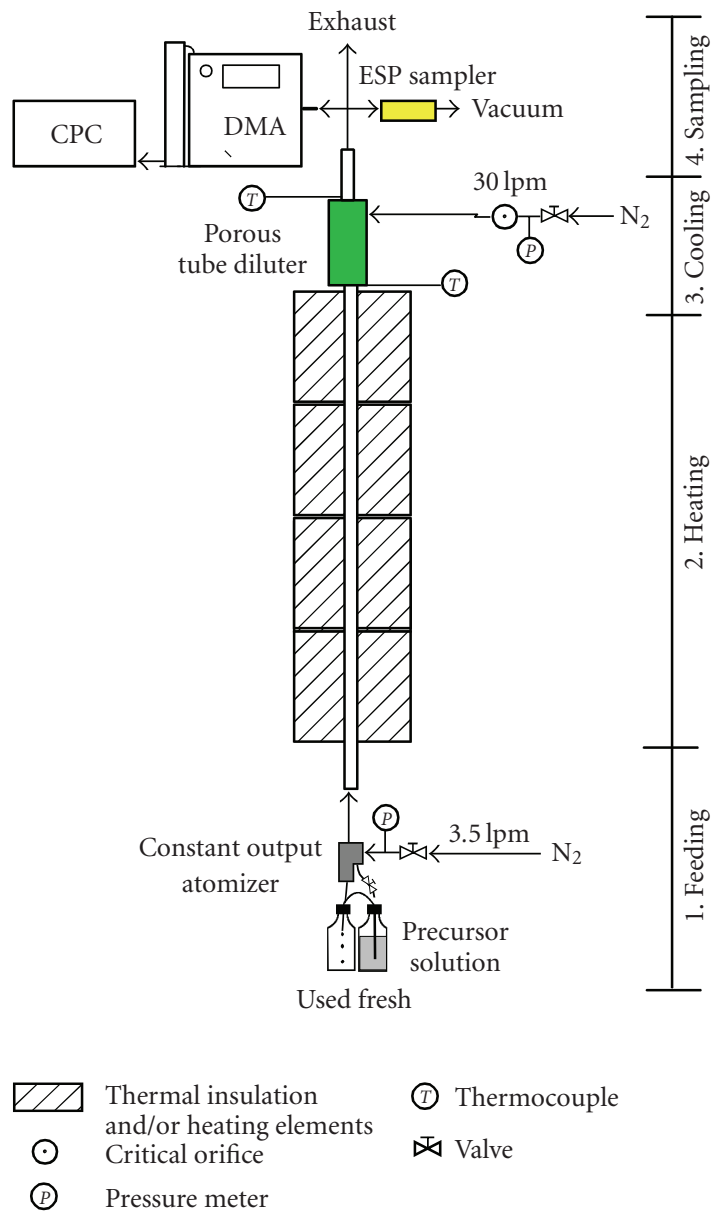

FIGURE 1: The experimental of the aerosol flow reactor used in the particle production.

particles. Complete mixing of aerosol and dilution gas before particle sampling was ensured with a mixing tube with an inner diameter of $9.6 \mathrm{~mm}$ and length of $250 \mathrm{~mm}$. The flow Reynolds number in the diluter and the mixing tube ( $\operatorname{Re} \sim 4550)$ indicated turbulent flow.

\subsection{Instrumentation and characterisation}

The particle number size distributions were measured with a differential mobility analyser, DMA (model 3081, TSI Inc. Particle Instruments, USA) connected to a condensation nucleus counter, CPC (model 3022, TSI Inc. Particle Instruments, USA). Particle samples were collected with a point-toplate electrostatic precipitator, ESP (InTox Products, USA) on carbon-coated copper grids. The morphology of the particles was studied with a transmission electron microscope, TEM (Philips CM-200, FEG/STEM, FEI Company, The Netherlands) and a field-emission low-voltage scanning electron microscope, FE-SEM (Leo Gemini DSM982, Leo Electron Microscopy Inc., Germany). The crystallinity of the individual particles was analysed from the electron diffraction patterns by TEM. For the SEM imaging, the samples were coated with platinum to increase the stability 
TABLE 1: Characteristics of L-leucine nanoparticles produced using different precursor solution concentrations and at different temperatures in the reactor heated zone.

\begin{tabular}{|c|c|c|c|c|c|c|c|c|c|c|c|c|c|c|}
\hline \multirow{2}{*}{$C_{\mathrm{le}}[\mathrm{g} / \mathrm{l}]$} & \multirow{2}{*}{$C_{\text {reactor }}\left[\mathrm{g} / \mathrm{m}^{3}\right]$} & \multicolumn{5}{|c|}{$T_{\text {reactor }}=110^{\circ} \mathrm{C}$} & \multicolumn{4}{|c|}{$T_{\text {reactor }}=150^{\circ} \mathrm{C}$} & \multicolumn{4}{|c|}{$T_{\text {reactor }}=200^{\circ} \mathrm{C}$} \\
\hline & & $S_{\max }^{\prime}$ & $d_{\mathrm{g}}[\mathrm{nm}]$ & $d_{\mathrm{m}}[\mathrm{nm}]$ & GSD & $N\left[1 / \mathrm{cm}^{3}\right]$ & $S_{\max }^{\prime}$ & $d_{\mathrm{g}}[\mathrm{nm}]$ & GSD & $N\left[1 / \mathrm{cm}^{3}\right]$ & $S_{\max }^{\prime}$ & $d_{\mathrm{g}}[\mathrm{nm}]$ & GSD & $N\left[1 / \mathrm{cm}^{3}\right]$ \\
\hline 1.1 & 0.012 & 38 & 99 & 418 & 2.0 & $5.8 \times 10^{5}$ & 0.48 & 31 & 1.8 & $2.7 \times 10^{5}$ & 0.0058 & 28 & 1.7 & $1.9 \times 10^{5}$ \\
\hline 2.2 & 0.029 & 93 & 123 & 520 & 2.0 & $8.1 \times 10^{5}$ & 1.16 & 61 & 1.5 & $5.1 \times 10^{5}$ & 0.014 & 35 & 1.5 & $3.5 \times 10^{5}$ \\
\hline 4.3 & 0.065 & 208 & 135 & 571 & 2.0 & $7.8 \times 10^{5}$ & 2.61 & 105 & 1.4 & $3.6 \times 10^{5}$ & 0.032 & 63 & 1.8 & $6.5 \times 10^{5}$ \\
\hline 8.6 & 0.143 & 455 & 142 & 600 & 2.0 & $6.9 \times 10^{5}$ & 5.79 & 180 & 1.5 & $3.1 \times 10^{5}$ & 0.070 & 109 & 1.9 & $6.7 \times 10^{5}$ \\
\hline 17.2 & 0.318 & 1020 & 150 & 782 & 2.1 & $8.2 \times 10^{5}$ & 12.8 & 209 & 1.7 & $3.4 \times 10^{5}$ & 0.16 & 162 & 1.9 & $1.7 \times 10^{6}$ \\
\hline
\end{tabular}

$C_{\mathrm{le}}$ is leucine concentration in the precursor solution, $C_{\text {reactor }}$ is the actual leucine concentration in the reactor, $T_{\text {reactor }}$ is the temperature in the heated zone, $S_{\max }^{\prime}$ is a descriptive saturation ratio (not a real condition) that would be obtained, if all L-leucine was in the vapour phase under these conditions, $d_{\mathrm{g}}$ is the geometric mean diameter, $d_{\mathrm{m}}$ is the mass median diameter calculated from $d_{\mathrm{g}}$ using a Hatch-Choate conversion equation for log-normal size distributions given in literature [17], GSD is the geometric standard deviation, and $N$ is the particle number concentration.

of the particles in the electron beam. The chemical identity of the L-leucine powder before and after the experiments was studied with ${ }^{1} \mathrm{H}$ - and ${ }^{13} \mathrm{C}-\mathrm{NMR}(200 \mathrm{MHz}$ Varian Gemini 2000, Varian Inc. Corporate, USA) using $\mathrm{D}_{2} \mathrm{O}$ as the solvent. The NMR studies confirmed that the chemical composition of L-leucine did not change during the particle production.

\subsection{Reactor conditions}

\subsubsection{Saturation ratio of L-leucine in the reactor}

The vapour pressure and saturation ratio of L-leucine in the reactor were calculated using the enthalpy of sublimation $\left(\Delta H_{\text {sub }}=150.7 \mathrm{~kJ} / \mathrm{mol}\right.$ at $\left.T_{\text {sub }}=455 \mathrm{~K}\right)$ according to Svec and Clyde [13]; and it is described in detail in the article of Raula et al. [8]. The vapour pressure and saturation ratio of water in the reactor were calculated using same method and using the saturation vapour pressure of water given in the literature [14]. The saturation ratios of water remained well below zero $\left(2 \times 10^{-7}\right)$ for all reactor conditions including the cooling section of the reactor.

\subsubsection{Vaporisation of L-leucine from the dry particles in the heated zone}

The evaporation time of L-leucine from the dry particles (i.e. particles contain no water) in the heated zone of the reactor was estimated using a diffusional transport equation according to Flagan and Seinfeld [15]:

$$
\frac{d D_{p}}{d t}=\frac{4 D_{v} M}{R \rho_{p} T D_{p}}\left(p_{\text {inf }}-p_{p s}\right) \beta_{\mathrm{FS}},
$$

where $D_{p}$ is the particle diameter, $t$ is time, $D_{v}$ is the diffusion coefficient of the L-leucine vapour, $M$ is the molecular weight of L-leucine, $R$ is the gas constant, $\rho_{p}$ is the particle density, $T$ is the reactor temperature, $p_{\text {inf }}$ is the L-leucine vapour pressure in the environment far away from the particle, $p_{p s}$ is the vapour pressure over the particle surface, and $\beta_{\mathrm{FS}}$ is the Fuchs-Sutugin interpolation factor for bridging the equations for continuum and the free molecular regions during the particle size change due to evaporation of Lleucine as described by Fuchs and Sutugin [16]. $p_{\text {inf }}$ is calculated based on the transfer of L-leucine to the gas phase by vaporisation of the particle and it is assumed to be zero at the beginning of calculations. The size $\left(d_{\mathrm{g}}\right)$ and number concentration $(N)$ of L-leucine particles produced at $110^{\circ} \mathrm{C}$ were used as the input in the calculations. The particles were assumed to be spheres with monodisperse size distribution (GSD $=1$ ). In $(1)$, the particle diameter $\left(D_{p}\right)$ is the mass median diameter $\left(d_{\mathrm{m}}\right)$. Accordingly, the geometric number mean diameters were converted using a Hatch-Choate conversion equation (HC) [17] into mass median diameters (see Table 1) that were used as the initial particle diameters $\left(d_{\mathrm{mi}}\right)$. This gives slight overestimate of the mass median diameter. The number of particles was the average of the particle concentrations $\left(N=7.4 \times 10^{5} 1 / \mathrm{cm}^{3}\right)$ and it was used together with $d_{m}$ to calculate iteratively $p_{\text {inf }}$. The particle density was assumed to be the same as the density of crystalline L-leucine $\left(1.293 \mathrm{~g} / \mathrm{cm}^{3}\right)$ given in literature [18]. No wall losses were taken in to account in the calculations. The amount of L-leucine vapour in the heated zone increases as the particle size decreases with time in the calculations as long as the saturation vapour pressure is reached. Instantaneous and perfect mixing is assumed in the calculations.

Fuchs-Sutugin interpolation factor $\beta_{\mathrm{FS}}$ is calculated as

$$
\beta_{\mathrm{FS}}=\frac{1+\mathrm{Kn}}{1+1.71 \times \mathrm{Kn}+1.333 \times \mathrm{Kn}^{2}},
$$

where $\mathrm{Kn}$ is a Knudsen number for the particle and is calculated iteratively for the decreasing particle size with the following equation:

$$
\mathrm{Kn}=\frac{2 \lambda}{D_{p}} .
$$

The diffusion coefficient of the vapour was estimated using the equation derived from literature [17]:

$$
D_{v}=\frac{2}{3 \mathrm{nd}_{c}^{2}} \sqrt{\frac{R T}{\pi^{3} M}},
$$

where $n$ is the number of vapour molecules taken to be the same as the number of gas molecules $\left(2.5 \times 10^{25} 1 / \mathrm{m}^{3}\right)$ and $d_{\mathrm{c}}$ is the collision diameter of the molecule that is considered to be the same as the diameter of the molecule that is $6.8 \AA$ derived from the literature [19]. 
The Kelvin effect expresses the increase in vapour pressure over a curved surface. The vapour pressure over the particle surface $\left(p_{p s}\right)$ is the product of the vapour pressure over the flat surface $\left(p_{s}\right)$ :

$$
p_{p s}=p_{s} \exp \left(\frac{4 \gamma M}{\rho_{p} R T D_{p}}\right),
$$

where $\gamma$ is surface tension or surface free energy. Since there are no data available on the surface free energy of Lleucine, the surface tension of the $17.2 \mathrm{~g} / \mathrm{L}$ aqueous solution of L-leucine was used instead. This concentration is very close to the solubility limit of L-leucine in ion-exchanged water. The measured surface tension of the L-leucine solution $(67 \mathrm{mN} / \mathrm{m})$ agrees well with the literature values of Gliński et al. [20]. A similar assumption is also made in studies of Lechuga-Ballesteros and Kuo [6].

\section{RESULTS}

\subsection{Reactor conditions}

Figure 2 shows the vapour pressures of L-leucine in the reactor at concentrations between 0.012 and $0.32 \mathrm{~g} / \mathrm{m}^{3}$ as well as the equilibrium vapour pressure of L-leucine in the temperature range 120 and $200^{\circ} \mathrm{C}$ calculated using equations and methods introduced by Raula et al. [8]. Accordingly, the evaporation of L-leucine begins when the temperature is raised above $140^{\circ} \mathrm{C}$; and L-leucine is completely vaporised in all concentrations when the temperature is above $180^{\circ} \mathrm{C}$ within the studied concentration range. An infinite residence time is assumed in these calculations. Table 1 lists the saturation ratios $\left(S_{\max }^{\prime}\right)$ for the different concentrations of L-leucine assuming that all L-leucine is vaporised. $S_{\max }^{\prime}>1$ indicates how far the condition in the heated zone is from the actual L-leucine vaporisation.

In the cooling zone, the cooling rates of the aerosol were 210 and $293^{\circ} \mathrm{C} / \mathrm{s}$ from 150 and $200^{\circ} \mathrm{C}$ to ambient temperature $\left(T=22^{\circ} \mathrm{C}\right)$. The rapid cooling induced a sudden change in saturation conditions leading to the supersaturation of Lleucine vapour. This resulted in saturation ratios temporarily far above unity (from 24.8 to 310 ) based on calculations of saturation ratios using equations and methods introduced in Raula et al. [8]. Instantaneous perfect mixing was assumed; and the possible temperature gradient between the centre line and the walls was not taken into account.

\subsection{Vaporisation of L-leucine from the dry particles in the heated zone}

Figures 3(a) and 3(b) show the change in size of the particles due to the evaporation of L-leucine at 150 and $200^{\circ} \mathrm{C}$. In general, the time needed for the particle size to reach an equilibrium state was short compared to the residence time in the heated zone of the reactor. At $200^{\circ} \mathrm{C}$, the time needed for complete evaporation ranged from 11 to 38 milliseconds for particle sizes of 418 and $782 \mathrm{~nm}$, respectively (see Figure 3(b)). The reduction rate of the particle size decreased from 38 to $20 \mathrm{~nm} / \mathrm{ms}$ as the initial particle size increased from 418 to $782 \mathrm{~nm}$.

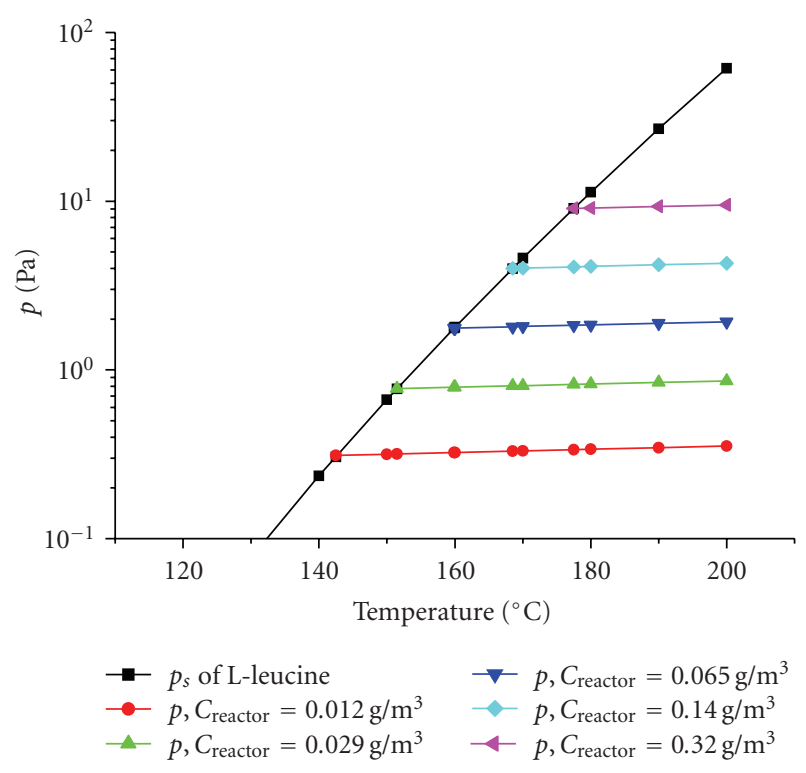

FIGURE 2: Vapour pressures and saturation vapour pressures $\left(p_{s}\right)$ L-leucine under different experimental conditions.

Based on the estimated saturation ratio (0.48) for Lleucine at $150^{\circ} \mathrm{C}$ calculated according to Raula et al. [8] Lleucine was expected to vaporise completely at the lowest concentration $\left(C_{\text {reactor }}\right.$ of $\left.0.012 \mathrm{~g} / \mathrm{m}^{3}\right)$. However the calculations with the diffusional transport equation (1) showed only partial vaporisation producing residual particles of $260 \mathrm{~nm}$, see Table 2 . The time required to reach equilibrium size was notably longer than at $200^{\circ} \mathrm{C}$ varying from 3 to 0.8 seconds for particle sizes of 418 and $782 \mathrm{~nm}$, respectively. According to the calculations, complete evaporation of Lleucine with initial particle size of $418 \mathrm{~nm}$ corresponding to a concentration of $0.012 \mathrm{~g} / \mathrm{m}^{3}$ took place at $157^{\circ} \mathrm{C}$ in 606 milliseconds.

\subsection{Number size distributions}

Table 1 shows the characteristics of the particles produced at different reactor temperatures and L-leucine concentrations $\left(C_{\text {reactor }}\right)$. The size distributions of particles produced at $110^{\circ} \mathrm{C}$ are shown in Figure 4 . At $110^{\circ} \mathrm{C}$, the solute droplets were merely dried. The geometric number mean diameter $\left(d_{\mathrm{g}}\right)$ of the particles increased from 99 to $150 \mathrm{~nm}$ with increasing L-leucine concentration (Table 1). The GSDs were around 2 at every concentration. The number concentration of particles $(N)$ varied only slightly between the experiments and was on average $7.4 \times 10^{5} \mathrm{~L} / \mathrm{cm}^{3}$. The size distributions were unimodal and close to symmetrical, that is, $d_{\mathrm{g}}$ was very close to the count median diameter (CMD) obtained in the measurements with only a few nanometres difference in all cases. Therefore, the corresponding mass mean diameters of the size distribution (see Table 1) were calculated with Hatch-Choate equation described by Hinds [17].

Figure 5 shows the number size distributions of the L-leucine particles produced at $150^{\circ} \mathrm{C}$. According to the 


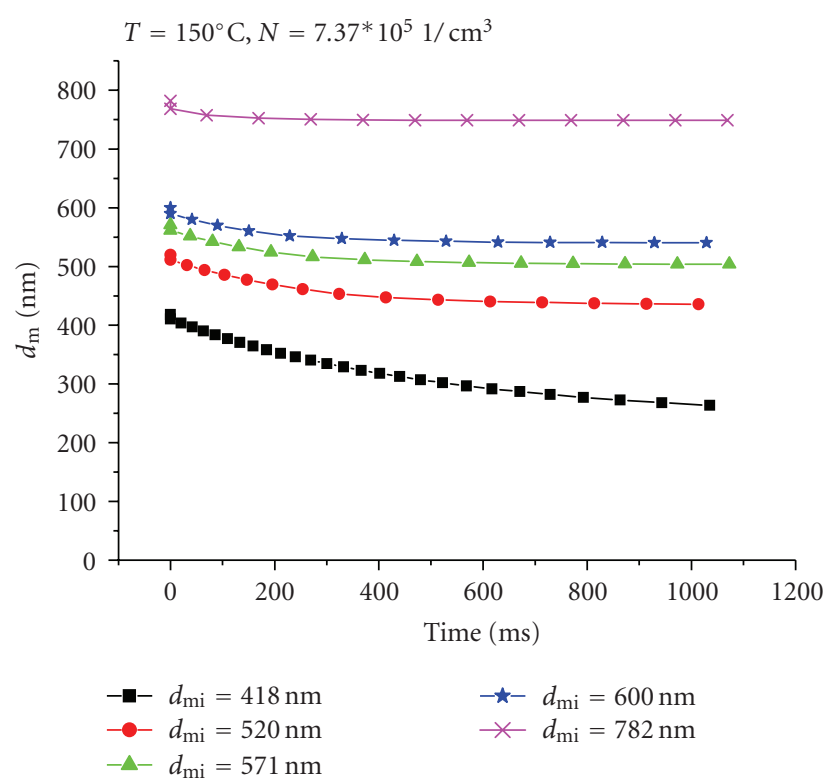

(a)

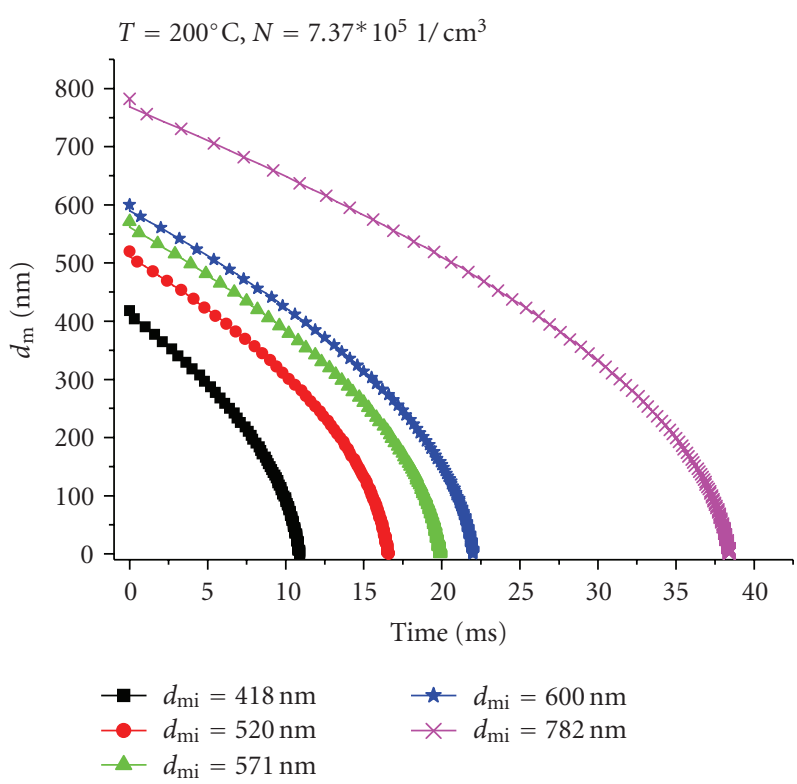

(b)

FIgUre 3: Calculated size reduction of L-leucine particles with different initial particle size as a function of time at (a) $150^{\circ} \mathrm{C}$ and $(\mathrm{b}) 200^{\circ} \mathrm{C}$.

TABLE 2: The comparison of the vaporisation of L-leucine from the particles in the heated zone of the reactor in the current and previous study of Raula et al. [8]. Experimentally derived particle number concentrations in the calculations were $7.4 \times 10^{5}$ in this study and $8.5 \times 10^{5}$ in Raula et al. [8].

\begin{tabular}{l|ccccc|crrr}
\hline & \multicolumn{4}{|c|}{ This study } & \multicolumn{3}{c}{ Raula et al. [8] } \\
\hline$C_{\text {reactor }}\left[\mathrm{g} / \mathrm{m}^{3}\right]$ & 0.012 & 0.029 & 0.065 & 0.143 & 0.318 & 0.02 & 0.09 & 0.22 & 1.34 \\
\hline$d_{\mathrm{m}}[\mu \mathrm{m}]$ & 0.42 & 0.52 & 0.57 & 0.60 & 0.78 & 0.80 & 1.35 & 1.69 & 2.41 \\
\hline$d_{\text {res }}$ at $150^{\circ} \mathrm{C}[\mu \mathrm{m}]$ & 0.26 & 0.44 & 0.50 & 0.54 & 0.75 & 0.78 & 1.34 & 1.69 & 2.4 \\
\hline $\begin{array}{l}\text { Time needed for complete } \\
\text { vaporisation at } 200^{\circ} \mathrm{C}[\mathrm{ms}]\end{array}$ & 10.9 & 16.6 & 19.9 & 22.0 & 38.4 & 41.4 & 278.9 & n.a. & n.a. \\
\hline
\end{tabular}

$N$ is the number of particles in the calculations for all concentrations, $d_{\mathrm{m}}$ is the mass median diameter at $110^{\circ} \mathrm{C}$ calculated from $d_{\mathrm{g}}$ using a Hatch-Choate conversion equation for log-normal size distributions given in literature [17], $d_{\text {res }}$ is the size of the residual particles obtained from the calculation with (1), n.a. = not applicable.

calculated saturation ratio, L-leucine was completely vaporised only with the lowest concentration of L-leucine, that is $0.012 \mathrm{~g} / \mathrm{m}^{3}$, while at higher concentrations than that, Lleucine was partially vaporised. $d_{\mathrm{g}}$ of the particles increased from 31 to $209 \mathrm{~nm}$ with increasing L-leucine concentration and the GSD varied between 1.4 and 1.8. $N$ did not change notably with respect to the L-leucine concentration and was between $2.7 \times 10^{5}$ and $5.1 \times 10^{5} \mathrm{~L} / \mathrm{cm}^{3}$. The size distributions were close to log-normal except for the highest concentration where a bimodal distribution was obtained.

Figure 6 shows the number size distributions of the particles from the reactor at $200^{\circ} \mathrm{C}$, where L-leucine was completely vaporised at all concentrations according to $S$ (see Figure 2). $d_{\mathrm{g}}$ of the particles increased from 28 to 162 $\mathrm{nm}$ and $N$ increased from $1.9 \times 10^{5}$ to $1.7 \times 10^{6} \mathrm{~L} / \mathrm{cm}^{3}$ with increasing L-leucine concentration. With the two lowest Lleucine concentrations, the size distributions were unimodal. With $C_{\text {reactor }}$ of $0.065 \mathrm{~g} / \mathrm{m}^{3}$ and above, bimodality in the distributions was observed.

\subsection{Shape and structure of L-leucine nanoparticles}

Figures 7(a) and 8(a) show SEM images of L-leucine nanoparticles produced with the highest concentration of L-leucine $\left(0.32 \mathrm{~g} / \mathrm{m}^{3}\right)$ from the reactor at 110 and $150^{\circ} \mathrm{C}$, respectively. The sizes of the particles are in a good agreement with volume-based median diameters calculated by HatchChoate conversion equations [17]: the diameters ranged from 418 to $782 \mathrm{~nm}$. In both cases, the particles appeared collapsed and partially fractured indicating that particles are produced by droplet drying. TEM images (Figures 7(b) and 8 (b)) show relatively low contrast in the central areas of the particles so that the supporting film underneath can be clearly seen. For this to happen with this size of particles, the particle shell has to be very thin which indicates low particle density. Figures 9(a) and 9(b) show the SEM and TEM images, respectively, of L-leucine nanoparticles produced at the highest concentration $\left(0.32 \mathrm{~g} / \mathrm{m}^{3}\right)$ with the temperature of the heated zone at $200^{\circ} \mathrm{C}$. At this temperature L-leucine 


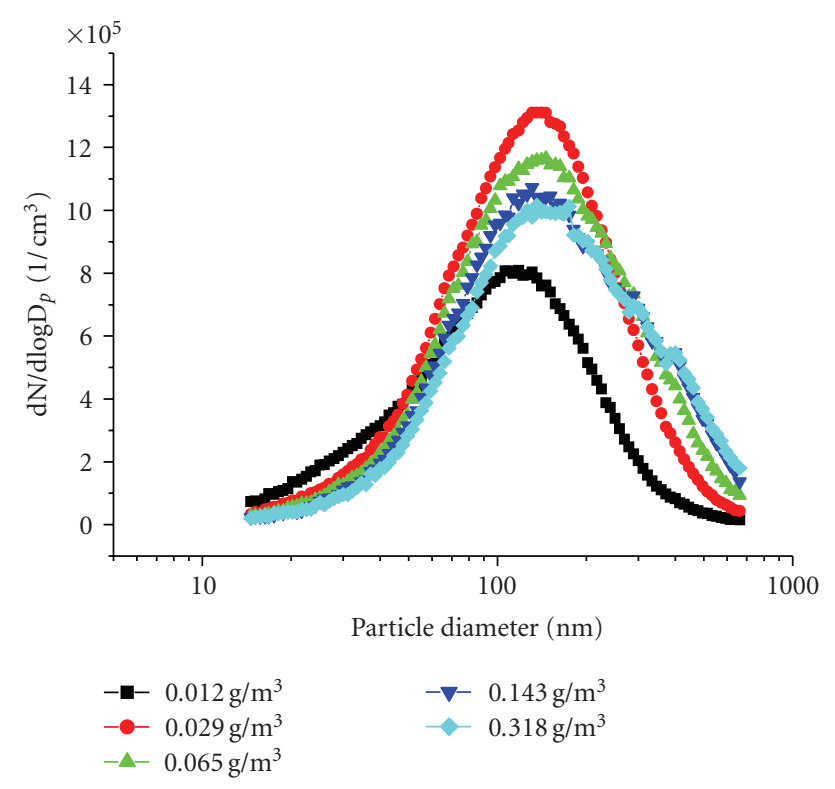

FIGURE 4: Number size distributions of L-leucine particles produced from the reactor at $110^{\circ} \mathrm{C}$. L-leucine concentration varied from 0.012 to $0.32 \mathrm{~g} / \mathrm{m}^{3}$.

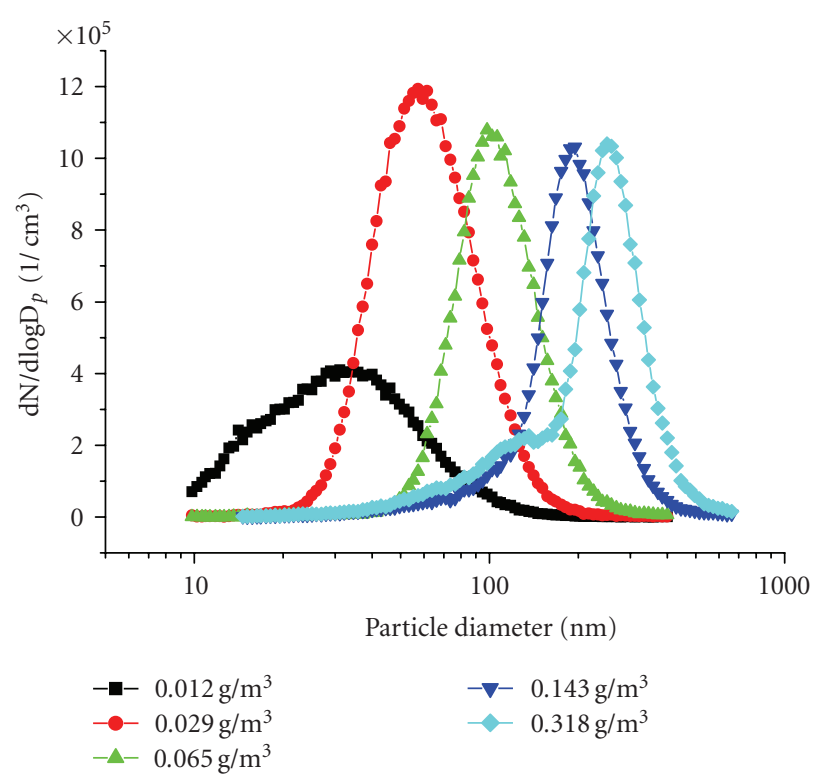

FIGURE 5: Number size distributions of L-leucine particles produced from the reactor at $150^{\circ} \mathrm{C}$. L-leucine concentration varied from 0.012 to $0.32 \mathrm{~g} / \mathrm{m}^{3}$.

vaporises and the particles were formed by the nucleation and condensation of the L-leucine vapour. The particles had a light, leafy-looking structure that is clearly different from the particle structures obtained at lower temperatures.

Electron diffraction patterns taken from a population of particles in TEM are shown as inserts in the corresponding TEM images (Figures 6-8(b)). The diffraction patterns indicate that the particles are crystalline despite the weak

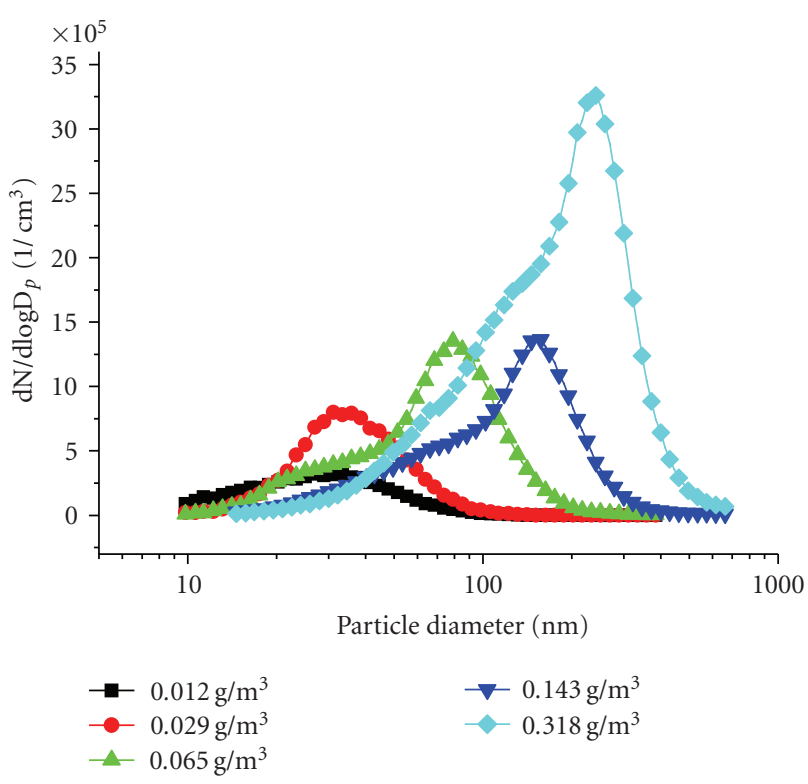

FIGURE 6: Number size distributions of L-leucine particles produced from the reactor at $200^{\circ} \mathrm{C}$. L-leucine concentration varied from 0.012 to $0.32 \mathrm{~g} / \mathrm{m}^{3}$.

contrast due to the deterioration of particles within a few seconds under the electron beam.

\section{DISCUSSION}

\subsection{Vaporisation of L-leucine depending on the particle size and temperature}

Table 2 shows the amount of L-leucine fed to the reactor and the changes in particle size due to the vaporisation of L-leucine calculated in this study and compared with the values of the previous study of Raula et al. [8]. Even though the particle number concentrations are of the same order of magnitude with only $13 \%$ difference, the initial droplet size in the experiments is considerably different. According to the manufacturer (TSI), the droplets around $300 \mathrm{~nm}$ are produced with the atomizer used in this study whereas the ultrasonic atomizer used by Raula et al. [8] generates micronsized droplets. This in turn affects the dry particle size as well as the amount of L-leucine vapour in the heated zone of the reactor.

According to the calculations at $150^{\circ} \mathrm{C}$, no vaporisation of L-leucine was observed with particles larger than $0.75 \mu \mathrm{m}$, that is, in the study of Raula et al. [8] and the largest particle size in this study. Below $0.75 \mu \mathrm{m}$, the calculations showed the partial vaporisation of L-leucine and formation of the residual particles with the mass median diameters $\left(d_{\text {res }}\right) 0.26$, $0.44,0.50$, and $0.54 \mu \mathrm{m}$ (Table 2). The partial vaporisation observed even with the smallest particle size corresponding to the lowest concentration is in contradiction with the saturation ratio that predicted complete vaporisation (Table 1). Since the amount of L-leucine in the reactor was derived from the total number of particles, particle size, and density as described in Section 2.4.2, the calculation is 


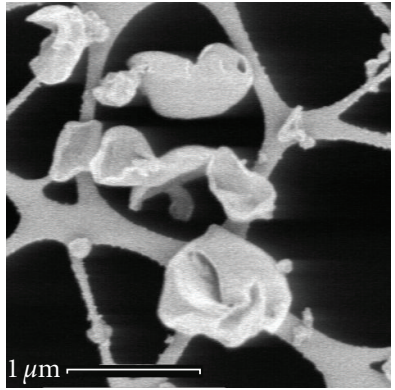

(a)

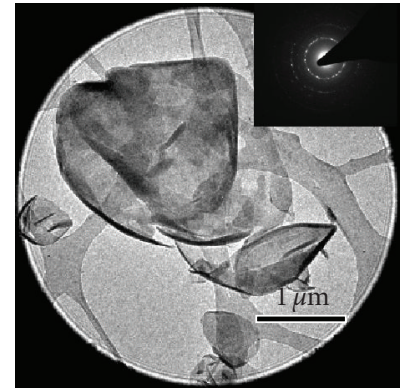

(b)

FIgURE 7: (a) SEM and (b) TEM images of L-leucine particles produced at $110^{\circ} \mathrm{C}$. Electron diffraction pattern indicating crystallinity is inserted in (b).

likely to give a slight overestimation of the amount of Lleucine in the reactor. One reason for this is the density value of crystalline bulk L-leucine used in the calculations compared to the hollow particle structure observed in TEM images. The repetition of the calculations at temperature of $157^{\circ} \mathrm{C}$ showed full vaporisation of L-leucine at the lowest concentration $\left(0.012 \mathrm{~g} / \mathrm{m}^{3}\right)$. This indicates that saturated conditions are close and only small variations may affect particle formation in these conditions.

A complete vaporisation of L-leucine was observed at $200^{\circ} \mathrm{C}$ for particles smaller than $1.69 \mu \mathrm{m}$. The time needed for the vaporisation increased exponentially with increasing particle size as the mass of L-leucine increased. The vaporisation of L-leucine decreases the particle size and it further accelerates the rate of vaporisation of the particles (see Figure 3(b)). This is understood by the Kelvin effect, which means that thermal transitions like melting and vaporisation of material requires less energy when particle size decreases [21-24]. For particles composed of organic material the Kelvin effect can be significant for particle sizes up to $200 \mathrm{~nm}$ [12].

\subsection{Formation of dry L-leucine particles}

At $110^{\circ} \mathrm{C}$, the particles were formed by droplet drying and the cooling of the aerosol did not affect the formation of the particles or the resulting particle size and size distribution. During the solvent evaporation, L-leucine accumulated on an air-water interface that, in this study, is the surface of the droplets. L-leucine is also known to spontaneously assemble as structured aggregates at the interfaces of the aqueous solution as described by Weissbuch et al. [25]. The rapid formation of the L-leucine surface layer caused the pressure build-up by the vaporisation of water expanding the surface layer. This resulted hollow, collapsed, and fractured particles with low density as observed also in the study of Raula et al. [8]. The volume-based median diameters of the particles coincide well with the observed particles.

The layer formation notably affected the size of L-leucine particles produced with a droplet-to-particle method at $110^{\circ} \mathrm{C}$. Let us assume that L-leucine particles are spherical with the density of crystalline L-leucine $\left(1.293 \mathrm{~g} / \mathrm{cm}^{3}\right)$.

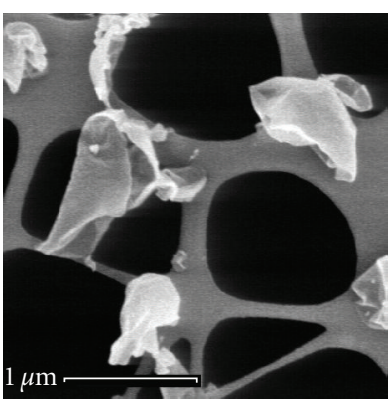

(a)

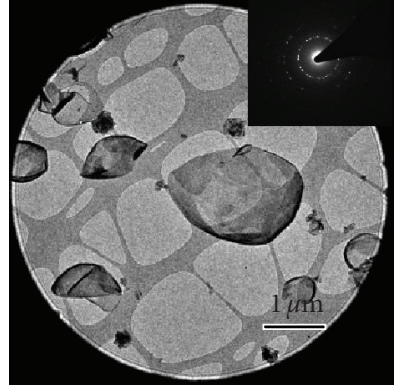

(b)
Figure 8: (a) SEM and (b) TEM images of L-leucine particles produced at $150^{\circ} \mathrm{C}$. Electron diffraction pattern indicating crystallinity is inserted in (b).

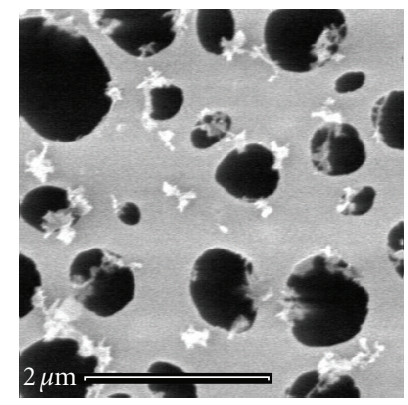

(a)

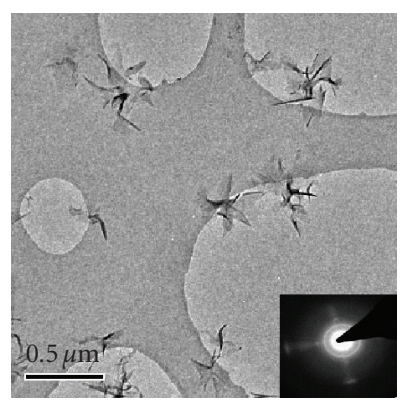

(b)
FIGURE 9: (a) SEM and (b) TEM images of L-leucine particles produced at $200^{\circ} \mathrm{C}$. Electron diffraction pattern indicating crystallinity is inserted in (b).

According to the manufacturer, the atomizer generates water droplets with diameter around $300 \mathrm{~nm}$. Based on these data, the sizes of the solid, spherical L-leucine particles for every solution concentration can be calculated. The diameter of the particles at a concentration of $0.012 \mathrm{~g} / \mathrm{m}^{3}$ was 3.6 times larger than the calculated size. The increase in the particle size was evidently caused by the expansion of the particle surface layer as discussed above. The size difference decreased with increasing L-leucine concentration, but was still 2.1 at the highest L-leucine concentration, $0.32 \mathrm{~g} / \mathrm{m}^{3}$. This indicates a very low density of the particles. The micronsized porous particles with the density as low as $0.4 \mathrm{~g} / \mathrm{cm}^{3}$ has been previously prepared by emulsification and solvent evaporation by Edwards et al. [26].

At $200^{\circ} \mathrm{C}$, L-leucine fully evaporated in the reactor at all concentrations. High supersaturation and subsequent homogeneous nucleation of the L-leucine vapour were obtained in the cooling zone. During the vapour deposition on the surface of the nuclei, L-leucine formed leafy-looking crystallites with sizes of a few nanometres with similar morphology of particles than observed by Raula et al. [8]. The heterogeneous deposition of L-leucine vapour is preferred on discontinuous spots such as edges and corners if present as studied by Rogers and Yau [27]. Apparently, the 
discontinuous domains for heterogeneous nucleation were created at the very beginning of the formation of stable nuclei by homogeneous nucleation of vapour resulting in crystal growth in a certain direction (see Figure 9). The number size distribution of the resulting particles was relatively narrow and unimodal at low L-leucine concentrations. The particle size was more dependent on the L-leucine concentration and it varied from $28 \mathrm{~nm}$ up to $162 \mathrm{~nm}$ compared to the particles prepared by Raula et al. [8] at $200^{\circ} \mathrm{C}$ with geometric mean diameters close to $100 \mathrm{~nm}$ in all cases except at the lowest concentration. Increasing the vapour concentration resulted in the appearance of shoulders in the distribution. This indicated that several nucleation modes were occurring along the cooling of the L-leucine vapour. There could be several reasons for that such as the trace amounts of unvaporised impurities in the precursor solution. Another reason is the temperature gradient in the cooling zone that was caused by the introduction of ambient nitrogen through the porous tube, that is, through the tube walls. The bimodal size distribution obtained at the high supersaturations of Lleucine vapour was due to the nonuniform temperature field and turbulent flow profile in the cooling and mixing zone as well as due to the slow diffusion of L-leucine vapour.

At the intermediate temperature of $150^{\circ} \mathrm{C}$, the extent of evaporation of L-leucine depended on the concentration as discussed in Sections 3.2 and 4.1. The saturated conditions are close and only small variations may affect particle formation. In fact, the size of the particles produced at the lowest concentration $\left(d_{\mathrm{g}}=31 \mathrm{~nm}\right)$ agreed well with the size obtained at $200^{\circ} \mathrm{C}$ with the same concentration and strongly indicated particle formation purely by vapour nucleation. The reactor conditions for L-leucine became saturated above a concentration of $0.037 \mathrm{~g} / \mathrm{m}^{3}$ corresponding to $2.0 \mathrm{~g} / \mathrm{L}$, at which the saturation ratio was unity. A fraction of the vaporised L-leucine $\left(0.037 \mathrm{~g} / \mathrm{m}^{3}\right)$ was deposited on the surface of the residual, unvaporised solid L-leucine particles via heterogeneous vapour deposition. The particle size was clearly dependent on both the L-leucine concentration and on the vapour deposition of the L-leucine vapour on the residual particles. Narrow-size distributions (GSD 1.4-1.5) were the result of the effective heterogeneous vapour deposition of L-leucine. In heterogeneous condensation/vapour deposition, which is the reverse of size decrease by evaporation described in (1), the smaller particles grow faster compared to larger particles narrowing the size distribution as described by Hinds [17]. However, the small amount of L-leucine vapour deposited on the particle surfaces was not a major factor determining the particle size at high L-leucine concentrations $\left(0.14\right.$ and $\left.0.32 \mathrm{~g} / \mathrm{m}^{3}\right)$. These concentrations yielded particle sizes larger than those produced at $110^{\circ} \mathrm{C}$ as summarised in Table 1. This difference in size can be explained by the formation of the L-leucine layer on the droplet surface that increased vapour pressure of the solvent water inside the droplet with the elevated temperature in the heated zone. This led to further expansion of the Lleucine surface layer during drying. The second mode as a shoulder in the size distribution at $0.32 \mathrm{~g} / \mathrm{m}^{3}$ in the reactor at $150^{\circ} \mathrm{C}$ may denote the appearance of fractured particles as was observed also in SEM images (Figure 8).

\section{CONCLUSIONS}

The production and formation of L-leucine nanoparticles under various conditions have been studied using the aerosol flow reactor method. The particle formation and growth mechanisms depended on the L-leucine saturation conditions in the reactor. At $110^{\circ} \mathrm{C}$, low-density particles were formed by droplet drying. The particle size was determined solely by the precursor solution concentration with $d_{\mathrm{g}}$ between 99 and $150 \mathrm{~nm}$. At $15^{\circ} \mathrm{C}$, L-leucine was partially vaporised and some unvaporised material remained in residual particles. The particle size increased from $31 \mathrm{~nm}$ up to $209 \mathrm{~nm}$. The particle size depended not only on the precursor solution concentration but also on the heterogeneous condensation of L-leucine vapour on the residual particles. At $200^{\circ} \mathrm{C}$, L-leucine was entirely vaporised at all precursor concentrations and the particle size varied from $30 \mathrm{~nm}$ to $210 \mathrm{~nm}$. The vaporisation of L-leucine was faster compared to the previous studies. Furthermore, the particle size was more dependent on the amount of L-leucine in the reactor. The particles were formed by homogeneous nucleation of Lleucine vapour causing the formation of leaf-like, crystalline nanoparticles as also observed previously.

\section{ACKNOWLEDGMENTS}

The authors would like to thank Academy of Finland for financial support. The authors also wish to thank Doctor Hua Jiang for work with the transmission electron microscope and Doctor Jouni Pyykönen for valuable help in calculations.

\section{REFERENCES}

[1] P. Lucas, K. Anderson, and J. N. Staniforth, "Protein deposition from dry powder inhalers: fine particle multiplets as performance modifiers," Pharmaceutical Research, vol. 15, no. 4, pp. 562-569, 1998.

[2] P. Lucas, K. Anderson, U. J. Potter, and J. N. Staniforth, "Enhancement of small particle size dry powder aerosol formulations using an ultra low density additive," Pharmaceutical Research, vol. 16, no. 10, pp. 1643-1647, 1999.

[3] J. Raula, J. A. Kurkela, D. P. Brown, and E. I. Kauppinen, "Study of the dispersion behaviour of L-leucine containing microparticles synthesized with an aerosol flow reactor method," Powder Technology, vol. 177, no. 3, pp. 125-132, 2007.

[4] J. Raula, A. Lähde, and E. I. Kauppinen, "A novel gas phase method for the combined synthesis and coating of pharmaceutical particles," Pharmaceutical Research, vol. 25, no. 1, pp. 242-245, 2008.

[5] N. Y. K. Chew, B. Y. Shekunov, H. H. Y. Tong, et al., "Effect of amino acids on the dispersion of disodium cromoglycate powders," Journal of Pharmaceutical Sciences, vol. 94, no. 10, pp. 2289-2300, 2005.

[6] D. Lechuga-Ballesteros and M.-C. Kuo, "Dry powder compositions having improved dispersity," WO 01/32144, May 2001.

[7] J. N. Staniforth and D. A. V. Morton, "Magnesium stearate, a phospholipid, or an amino acid in preparation of pharmaceuticals for inhalation," patent application WO 02/43700, 2002. 
[8] J. Raula, A. Kuivanen, A. Lähde, et al., "Synthesis of Lleucine nanoparticles via physical vapor deposition at varying saturation conditions," Journal of Aerosol Science, vol. 38, no. 12, pp. 1172-1184, 2007.

[9] K. Meyer and I. Zimmermann, "Effect of glidants in binary powder mixtures," Powder Technology, vol. 139, no. 1, pp. 4054, 2004.

[10] S. Jonat, S. Hasenzahl, A. Gray, and P. C. Schmidt, "Mechanism of glidants: investigation of the effect of different colloidal silicon dioxide types on powder flow by atomic force and scanning electron microscopy," Journal of Pharmaceutical Sciences, vol. 93, no. 10, pp. 2635-2644, 2004.

[11] A. Gurav, T. Kodas, T. Pluym, and Y. Xiong, "Aerosol processing of materials," Aerosol Science and Technology, vol. 19, no. 4, pp. 411-452, 1993.

[12] J. H. Seifeld and S. N. Pandis, Atmospheric Chemistry and Physics: From Air Pollution to Climate Change, John Wiley \& Sons, Hoboken, NJ, USA, 2nd edition, 2006.

[13] H. J. Svec and D. D. Clyde, "Vapor pressures of some $\alpha$-amino acids," Journal of Chemical and Engineering Data, vol. 10, no. 2, pp. 151-152, 1965.

[14] F. P. Incropera and D. P. DeWitt, Fundamentals of Heat and Mass Transfer, John Wiley \& Sons, New York, NY, USA, 5th edition, 2002.

[15] R. C. Flagan and J. H. Seinfeld, Fundamentals of Air Pollution Engineering, Prentice Hall, Englewood Cliffs, NJ, USA, 1988.

[16] N. A. Fuchs and A. G. Sutugin, "High-dispersed aerosols," in Topics in Current Aerosol Research, G. M. Hidy and J. R. Brock, Eds., pp. 1-60, Pergamon Press, New York, NY, USA, 1971.

[17] W. C. Hinds, Aerosol Technology: Properties, Behavior, and Measurement of Airborne Particles, John Wiley \& Sons, New York, NY, USA, 2nd edition, 1999.

[18] S. Budavari, M. J. O’Neil, A. Smith, and P. E. Heckelman, Eds., The Merck Index: An Encyclopedia of Chemicals, Drugs, and Biologicals, Merck, Rahway, NJ, USA, 11th edition, 1989.

[19] K. Hasegawa, S. Miyashita, H. Komatsu, C. Sano, and N. Nagashima, "In-situ observation of the concentration gradient layer around a growing crystal of leucine complex," Journal of Crystal Growth, vol. 166, no. 1-4, pp. 925-929, 1996.

[20] J. Gliński, G. Chavepeyer, and J.-K. Platten, "Surface properties of aqueous solutions of L-leucine," Biophysical Chemistry, vol. 84, no. 2, pp. 99-103, 2000.

[21] K. Dick, T. Dhanasekaran, Z. Zhang, and D. Meisel, "Sizedependent melting of silica-encapsulated gold nanoparticles," Journal of the American Chemical Society, vol. 124, no. 10, pp. 2312-2317, 2002.

[22] Q. Jiang, H. X. Shi, and M. Zhao, "Melting thermodynamics of organic nanocrystals," The Journal of Chemical Physics, vol. 111, no. 5, pp. 2176-2180, 1999.

[23] S. L. Lai, J. Y. Guo, V. Petrova, G. Ramanath, and L. H. Allen, "Size-dependent melting properties of small tin particles: nanocalorimetric measurements," Physical Review Letters, vol. 77, no. 1, pp. 99-102, 1996.

[24] M. Zhao and Q. Jiang, "Melting and surface melting of lowdimensional in crystals," Solid State Communications, vol. 130, no. 1-2, pp. 37-39, 2004.

[25] I. Weissbuch, F. Frolow, L. Addadi, M. Lahav, and L. Leiserowitz, "Oriented crystallization as a tool for detecting ordered aggregates of water-soluble hydrophobic $\alpha$-amino acids at the air-solution interface," Journal of the American Chemical Society, vol. 112, no. 21, pp. 7718-7724, 1990.

[26] D. A. Edwards, J. Hanes, G. Caponetti, et al., "Large porous particles for pulmonary drug delivery," Science, vol. 276, no. 5320, pp. 1868-1872, 1997.
[27] R. R. Rogers and M. K. Yau, A Short Course in Cloud Physics, Pergamon Press, Oxford, UK, 3rd edition, 1989. 

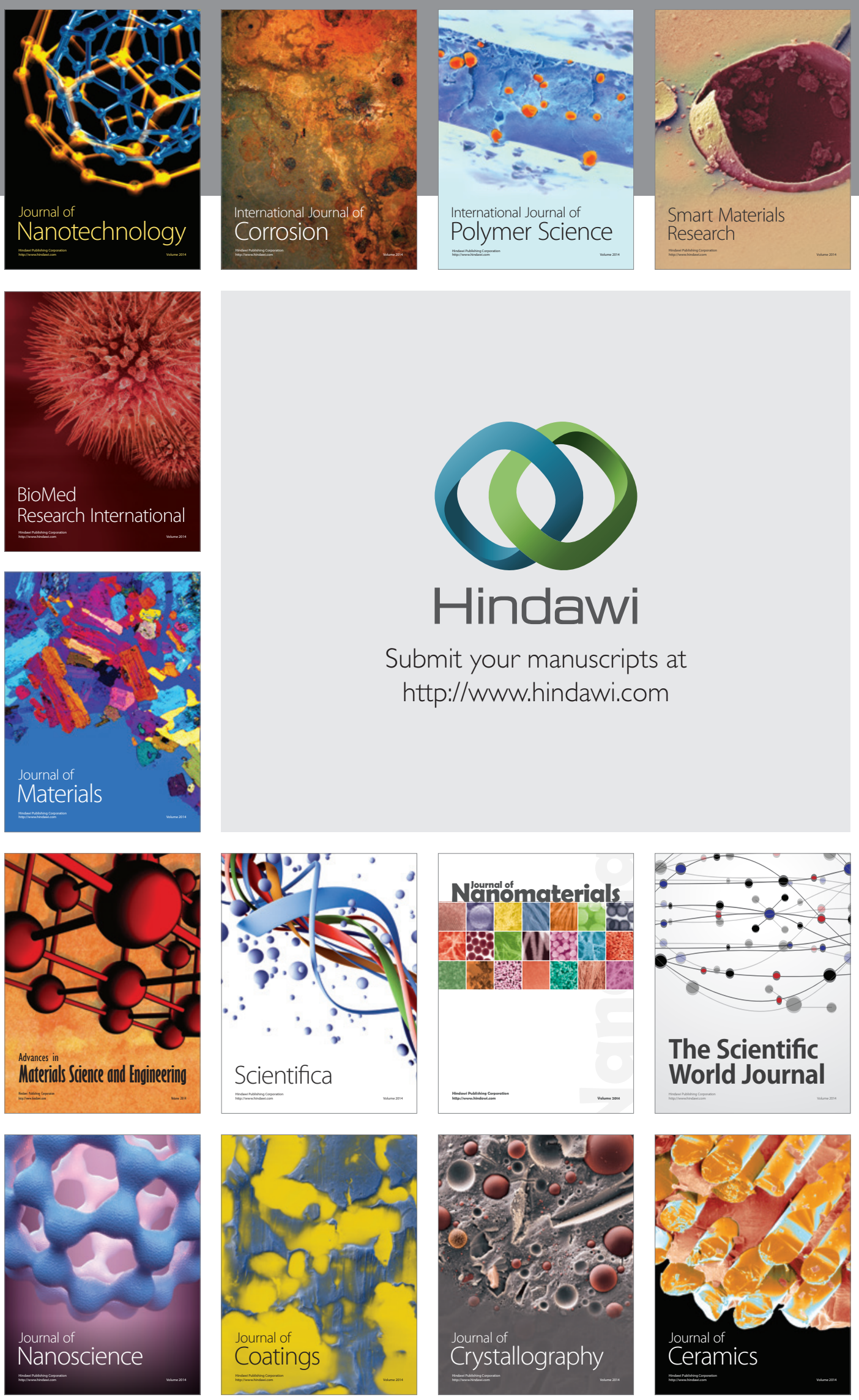

The Scientific World Journal

Submit your manuscripts at

http://www.hindawi.com

\section{World Journal}

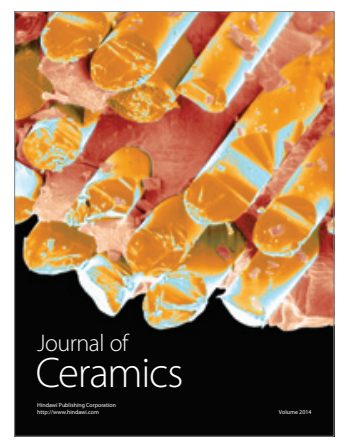

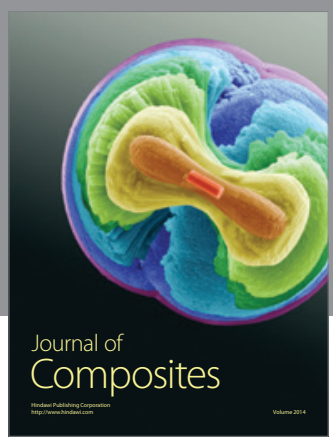
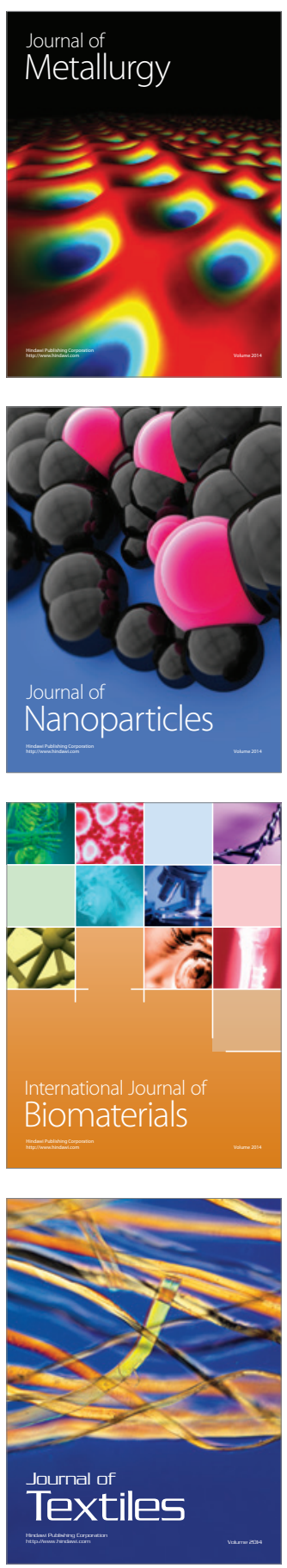